\title{
Evaluation of acute cardiovascular effects of propofol on hemodynamic function in pigs
}

\author{
This article was published in the following Dove Press journal: \\ Open Access Animal Physiology \\ 16 October 2012 \\ Number of times this article has been viewed
}

\author{
Nadine Pfeiffer ${ }^{1}$ \\ Johanna Ebner' \\ Anne-Kathrin von Thaden' \\ Tibor Schuster ${ }^{2}$ \\ Wolf Erhardt ${ }^{3}$ \\ Christine Baumgartner \\ 'Centre of Preclinical Research; \\ ${ }^{2}$ Institute for Medical Statistics \\ and Epidemiology; ${ }^{3}$ Institute for \\ Experimental Oncology and \\ Therapeutic Research, Technical \\ University of Munich, Munich, \\ Germany
}

Background: Although propofol is a common hypnotic in laboratory pigs, its acute effects on cardiovascular function have not been investigated in this species. Therefore, the short-term cardiovascular effects of intravenous propofol bolus injection were observed using vascular ultrasonography and pulse contour-derived cardiac output (PiCCO) thermodilution monitoring. Materials and methods: In this prospective, experimental study, anesthesia was induced and maintained intravenously with propofol in six pigs. During anesthesia, three defined bolus injections of propofol were given intravenously. Vascular and hemodynamic variables were recorded by capnometry, pulse oximetry, and ultrasonography of the right common carotid artery before injection and for 10 minutes after each propofol bolus injection. Additionally, body temperature, blood pressure and central venous pressure, cardiac output, contractility, volumetric variables for preload and afterload, and extravascular lung water were recorded by PiCCO.

Results: Propofol bolus injections caused a significant decrease in vessel diameter after 15 seconds at the right common carotid artery after each bolus injection. Simultaneously, peak systolic and end-diastolic blood flow velocities and heart rate significantly increased, while mean arterial blood pressure and systemic vascular resistance index significantly decreased. After these acute initial changes, vascular diameter reincreased towards baseline data and peak systolic blood-flow velocity significantly decreased, while mean arterial pressure and systemic vascular resistance index significantly increased until 10 minutes after bolus injection.

Conclusion: Bolus injections of propofol produced biphasic vascular and hemodynamic changes in pigs. However, these alterations were only associated with minor changes in cardiac output and did not lead to significant changes in volumetric flow, indicating well-preserved cardiovascular function, particularly of the baroreceptor reflex within the first 10 minutes after propofol bolus injection.

Keywords: anesthetics, propofol, cardiovascular, ultrasonography, pigs

\section{Introduction}

The short-acting hypnotic agent propofol (2,6-diisopropylphenol), which is commonly used in small-animal veterinary medicine for induction of anesthesia and maintenance of hypnosis, eg, in total intravenous anesthesia, is also used in experimental medicine in pigs. Induction and maintenance of anesthesia can be conducted with propofol. Anesthesia with propofol is easy to control because of its fast metabolism and minimal cumulative effects. ${ }^{1-5}$ However, propofol has no analgesic properties. Consequently, surgical procedures should only be carried out when propofol is combined with an analgesic. Known side effects of propofol causing hypotension are vasodilatation and a negative inotropic effect on the heart. In humans, propofol administration results in
Correspondence: Nadine Pfeiffer Centre of Preclinical Research, Klinikum rechts der Isar, Technical University of Munich, Ismaninger Str 22, Munich 81675, Germany Tel +498941404472 $\mathrm{Fax}+498941406182$ Email nadine_pfeiffer@freenet.de 
a reduction of the cardiac index and mean arterial pressure (MAP). ${ }^{6}$ This hypotension can be intensified when an opioid analgesic (eg, fentanyl) is given in combination with propofol.

Bolus injections of propofol are often used to prolong or deepen anesthesia. The direct short-term effects of a propofol bolus injection on the cardiovascular system have already been investigated in rabbits $^{7}$ based on cardiovascular ultrasound techniques. In the study reported here, advanced methods like pulse-contour cardiac output (PiCCO), which is commonly used in human intensive medicine, are used to verify the short-term cardiovascular effects (especially regarding the cardiac output and volumetric variables for preload and afterload) of propofol in pigs.

PiCCO combines two methods to evaluate hemodynamic parameters: a discontinuous method that is based on transcardiopulmonary thermodilution and a continuous method based on pulse-contour analysis. The thermodilution method uses an indicator, a defined volume of cold saline solution, which is administered in a central blood vessel, namely the jugular vein. Its concentration is measured downstream distally (eg, in the femoral artery) after passing the right heart side, the lungs, and the left heart side, and is finally recorded as a function of time - the thermodilution curve. In 1897, Stewart described for the first time the possibility of measuring blood flow via dilution of an indicator. ${ }^{8}$ Because of blood circulation, there is recirculation of the indicator, which causes imprecision in measuring. Hamilton found a solution for this problem in 1932 in creating the mono-exponential extrapolation of the dilution curve. Therefore, today the equation is called the Stewart-Hamilton equation. ${ }^{8}$

In 1930, Otto Frank created a method called pulse-contour analysis to measure the cardiac output (CO) of the heart based on his studies about wave mechanics and the air-chamber theory in 1899. Pulse-contour analysis is an indirect method based on the assumption that the curve of the arterial pressure and its trend resemble the devolution of blood flow. ${ }^{8}$ Via the modified Cz-analysis of Wesseling, ${ }^{9}$ the pulse contour is analyzed and the $\mathrm{CO}$ can be calculated. However, in contrast to the thermodilution technique, the pulse-contour analysis can be highly affected by hemodynamic instability. ${ }^{9-11}$

Using the PiCCO technique the following hemodynamic parameters can be measured: $\mathrm{CO}$, stroke volume (SV), heart rate (HR), SV variation (SVV), global end-diastolic volume index (GEDI), extravascular lung water index, systemic vascular resistance index (SVRI), maximum velocity of pressure rise in the aorta (dPmax), global ejection fraction (GEF), and cardiac index of function (CFI).
Within several studies, the use of the PiCCO technique has been validated for pigs comparing transcardiopulmonary thermodilution values with the pulmonary arterial thermodilution technique, which has been the gold standard in measuring hemodynamic variables. ${ }^{12-15}$ In these studies, PiCCO and the pulmonary arterial thermodilution technique led to collection of comparable data.

The objective of this study was to evaluate the direct, short-term vascular, and hemodynamic changes of intravenous bolus injections of propofol during propofol anesthesia in pigs.

\section{Materials and methods Animals}

This study was performed with the approval of the local animal care committee and carried out in accordance with the German Animal Welfare Act (Deutsches Tierschutzgesetz, 2010). Six 3-month-old female Landrace pigs from an experimental breeding colony (Versuchsstation Thalhausen, Germany) with a mean \pm standard deviation (SD) body weight of $34.7 \pm 3.9 \mathrm{~kg}$ were used in the study.

The pigs were housed under conventional hygienic conditions and acclimatized to the new environment for a period of 7 days. The room temperature was maintained at $19^{\circ} \mathrm{C} \pm 2{ }^{\circ} \mathrm{C}$ with a relative humidity of $50 \%-60 \%$. For enrichment, plastic balls were provided. A 12-hour/12-hour light-dark cycle was applied. Animals were offered a commercial pelleted diet (deuka Kornmast 130 gekoernt, Alleinfuttermittel für Mastschweine; Deutsche Tiernahrung Cremer, Regensburg, Germany) twice daily and received water ad libitum. Prior to anesthesia, animals were starved for 12 hours, but had free access to water.

\section{Anesthesia}

Experimental procedure was conducted between 8 am and noon. Sedation was induced by ketamine $10 \mathrm{mg} / \mathrm{kg}$ (Narketan 10; Vétoquinol, Ravensburg, Germany), azaperone $2 \mathrm{mg} / \mathrm{kg}$ (Stresnil; Janssen Animal Health, Neuss, Germany), and atropine $0.029 \mathrm{mg} / \mathrm{kg}$ (Atropin; B Braun, Melsungen, Germany) intramuscularly, mixed in one syringe. An intravenous catheter $(0.9 \times 25 \mathrm{~mm}$, Vasofix; B Braun $)$ was placed in the right and left lateral auricular vein. Anesthesia was induced with propofol $1.9 \pm 0.7 \mathrm{mg} / \mathrm{kg}$ (1\% MCT Fresenius; Fresenius Kabi Deutschland, Bad Homburg, Germany). Tracheal intubation was performed after loss of the swallowing reflex (inner diameter of endotracheal tube $7-7.5 \mathrm{~mm}$ ) and the precise body weight of the animal was ascertained. For preemptive analgesia, metamizole 
$40 \mathrm{mg} / \mathrm{kg}$ (Novaminsulfon-ratiopharm 2.5; Ratiopharm, Ulm, Germany) was given once intravenously (IV). Each pig was ventilated (Cicero; Draeger Medizintechnik, Luebeck, Germany) with $40 \%$ oxygen and a breathing rate of 12-17 times per minute, while the peak ventilation pressure was 15-20 Mbar. HR and peripheral arterial oxygen saturation $\left(\mathrm{SpO}_{2}\right)$ were monitored by use of a pulse oximeter ( 8600 V; Nonin Medical, Plymouth, MN). Further end-tidal $\mathrm{CO}_{2}$ and rectal body temperature were recorded (Cicero). Monitoring of the central venous pressure was conducted by use of a patient monitor (Datex Ohmeda S/5 type F-CM1.00 pressure transducers, Hellige type 4-327-I; Datex Ohmeda, Helsinki, Finland). Saline was infused IV at a maintenance rate of $10 \mathrm{~mL} / \mathrm{kg} /$ hour. All additional fluids for PiCCO measurements were subtracted from the infusion rate to retain the general maintenance rate of $10 \mathrm{~mL} / \mathrm{kg} / \mathrm{hour}$.

Pigs were positioned in dorsal recumbency to conduct ultrasonographic measurements of the right common carotid artery. Anesthesia was sustained by a continuous IV infusion of propofol (13.4 $\pm 2.1 \mathrm{~mL} / \mathrm{kg} /$ hour, $2 \%$ MCT Fresenius $)$. A stable plane of anesthesia was maintained with this dose, indicating good muscle relaxation and hypnosis with steady cardiovascular parameters: $\mathrm{HR}, \mathrm{MAP}, \mathrm{SpO}_{2}$, end-tidal carbon dioxide $\left(\mathrm{PetCO}_{2}\right)$, and ultrasonographic data.

\section{Experimental protocol}

For performing the PiCCO measurements, vascular catheters were inserted into the left external jugular vein (tube/X-ray line 50-cm CH08; Unomedical, Birkerd, Denmark) and into a superficial branch of the left iliac artery (PiCCO A brachialis catheter 16-cm 4F, PVPK2014 L16-46 N; Pulsion Medical Systems, Munich, Germany). Sufficient analgesia was achieved by remifentanyl continuous-rate infusion (0.007 mg/kg/h, Ultiva 5 mg; Glaxo Smith Kline, Munich, Germany). Remifentanyl infusion was stopped after the invasive procedures were finished. A washing-out period of remifentanyl of 10 minutes minimum was adhered to before stable baseline values were recorded.

Each part of the experiment began with measurement of baseline data. Baseline measurements were determined only after a stable anesthetic plane was evident. This means that values for $\mathrm{HR}, \mathrm{MAP}, \mathrm{PetCO}_{2}$, values recorded by $\mathrm{PiCCO}$, and ultrasonographic variables did not differ more than $5 \%$ from baseline values.

Three bolus injections of propofol $1 \%$ (3 mg/kg, IV) were applied at 25-minute intervals. Each bolus injection was administered over 10 seconds. Time 0 was defined as the end of each propofol injection. Vascular and hemodynamic changes were recorded after each of the three propofol bolus injections over 10 minutes (recorded time points: 15 seconds, $1,2,3,4,5,6,7,8,9,10$ minutes).

\section{Ultrasonography of the right common carotid artery}

An ultrasonographic system (Vivid 7; GE Vingmed Ultrasound, Horten, Norway) with a 10-MHz linear transducer (FLA 1-MHz 1A; GE Vingmed) was used to conduct vascular imaging of the right common carotid artery. The probe was placed on the right side of the ventral cervical region and adjusted until it showed explicit parallel vessel walls in the ultrasonic image of the common carotid artery. Then the probe was fixed in position with a clamp. Instrument settings were adjusted to delineate the vessel walls from surrounding tissues. Probe position was adjusted until distinct parallel vessel walls were visible. The Doppler sample volume was placed centrally in the vessel and the sample-volume cursor was adjusted to align with the vessel walls and blood flow. The angle between the sample-volume cursor and the ultrasound beam was measured by the ultrasound system and used to correct velocity calculations. An angle between $45^{\circ}$ and $60^{\circ}$ was consistently achieved between the vessel and the ultrasound beam. Once the sample volume was correctly positioned, Doppler studies were carried out in pulse-wave mode. Recorded velocity spectra were assessed for quality by clarity of the visual and audible signal and then stored to measure peak systolic blood-flow velocity (psBFV), minimum diastolic blood flow velocity, end-diastolic bloodflow velocity (edBFV), and average blood-flow velocity (Vave; calculated as the mean of all frequencies occurring above and below baseline from the velocity spectrum). From these, the average volumetric flow (VFave) was derived. Furthermore, two-dimensional images of the vessel wall were assessed and stored to measure the luminal diameter between the $\mathrm{V}$ means mean flow velocity leading edge of the innermost echogenic layer by cursor adjustment.

VFave in the right common carotid artery was calculated using the following equation: $V_{\text {mean }} \times \pi \times r^{2}$, in which $r$ is the vessel radius and Vmean is the mean velocity. ${ }^{16}$

\section{$\mathrm{PiCCO}$ thermodilution measurements}

Two methods are combined in this technique to evaluate hemodynamic parameters: a continuous method based on pulse-contour analysis and a discontinuous method based on transcardiopulmonary thermodilution.

Using the continuous method (pulse-contour analysis) the following parameters were recorded at time points 0.25 , 
$1,2,3,4,5,6,7,8,9$, and 10 minutes after propofol bolus injection: HR, arterial blood pressure (systolic, diastolic, and MAP), CO, SVRI, SVV, dPmax, and blood temperature.

The second method - transcardiopulmonary thermodilution - uses cold saline solution as an indicator. Ten $\mathrm{mL}$ of cold sodium chloride was injected at $1,2,4,6,8$, and 10 minutes after test bolus application of propofol into the left jugular vein via the PiCCO injection pin. The cold sodium chloride then passed the right heart, the lungs, and the left heart to finally arrive at the aorta and the femoral and iliac arteries at the thermistor probe placed in the superficial branch of the left iliac artery. CO, CFI, GEDI, extravascular lung water index, and the GEF were calculated by PiCCO using the thermodilution curve.

Consequently, there are two different methods for measuring $\mathrm{CO}$ via PiCCO technique included in this study: via thermodilution and via pulse-contour analysis. Compared to pressure-based methods of hemodynamic measurement, the PiCCO technique additionally provides volumetric variables. Index parameters are normalized to body surface or body weight.

$\mathrm{CO}$ is dependent on SV and HR. Furthermore, three different parameters affect SV: preload, afterload, and contractility. Regarding the PiCCO technique, the SVV indicates whether an increase of preload (eg, because of infusion) in a controlled ventilated patient is leading to an increase of $\mathrm{CO}$ or not. Another important parameter to define the preload of the heart using the PiCCO technique is the GEDI, which is the global end-diastolic volume (GEDV) normalized to body surface, indicating the effect of an infusion on the circulation. The SVRI is a parameter defining the afterload, and the parameters dPmax, GEF, and CFI define the contractility of the heart. The contractility of the left ventricle is described with dPmax. The GEF is calculated via the equation $4 \times \mathrm{SV} / \mathrm{GEDV}$. The CFI is the fraction of preload volume that is pumped by the heart in 1 minute. It is calculated by the equation CO/GEDV.

Simultaneously, during vascular ultrasound and PiCCO measurements, further clinical variables including $\mathrm{SpO}_{2}$, $\mathrm{PetCO}_{2}$ as well as rectal body temperature were recorded after each propofol bolus injection.

\section{Statistical evaluation}

Descriptive statistics (mean $\pm \mathrm{SD}$ ) are reported for all data. Statistical comparisons were made for an exploratory data analysis, thus no correction of type I error was considered. All statistical tests were conducted two-sided, and a
$P$-value less than 0.05 was considered to indicate statistical significance.

To evaluate overall time trends of interesting response variables, linear mixed regression models with monotonous (linear), transient (quadratic), and cubic time effects were fitted to the data. The linear mixed regression modeling approach properly reflects the structure of repeated data and accounts for correlation between measurements within the same subject. A first-order autoregressive correlation structure as well as random effects for each pig were considered in the regression analysis. Effects of time were first specified by graphic assessment and then verified by stepwise model derivation. When a specific effect of time was detected in the global trend analysis, a post hoc Student $t$-test for paired samples was used to assess differences between each time point during the 10-minute examination period and the baseline value. Furthermore, a Friedman test followed by paired Student $t$-tests were used to separately compare related samples given by equivalent time points after the first, second, and third bolus for the variables HR, MAP, SVRI, thermodilutional and pulse-contour CO, and SV. All statistical analyses were conducted with the commercially available software SPSS (version 19; IBM, Munich, Germany).

\section{Results}

\section{Ultrasonography of the right common carotid artery}

The data (mean $\pm \mathrm{SD}$ ) of the measurements at the right common carotid artery (CCA) after the first, second, and third propofol test bolus injections are shown in Tables 1-3. Propofol bolus injections caused a significant and transient decrease in vessel diameter at the CCA at the 0.25 -minute time point after each bolus injection (bolus 1, 9.2\% decrease compared to baseline; bolus 2, 11.2\% decrease compared to baseline; bolus 3, 7.5\% decrease compared to baseline). Simultaneously, psBFV and edBFV significantly increased. After these acute initial changes, vascular diameter reincreased towards baseline data and edBFV and psBFV (psBFV significantly after the first and second bolus injection compared to baseline data) decreased until 10 minutes after bolus injection. VFave slightly decreased at the 0.25 -minute time point after bolus injection, but not significantly and increased again continuously from 2 minutes after bolus injection. When all data were compared at equivalent time points after the first, second, and third bolus injections (see Tables 1 and 2), there were no differences in luminal diameter (D) and VFave. Significant differences 
Table I Ultrasonographic evaluation of the right common carotid artery after the first propofol bolus injection (mean \pm standard deviation)

\begin{tabular}{|c|c|c|c|c|}
\hline $\begin{array}{l}\text { Time } \\
\text { (minutes) }\end{array}$ & $\begin{array}{l}\text { D } \\
(\mathrm{mm})\end{array}$ & $\begin{array}{l}\text { psBFV } \\
\text { (cm/second) }\end{array}$ & $\begin{array}{l}\text { edBFV } \\
\text { (cm/second) }\end{array}$ & $\begin{array}{l}\text { VFave } \\
\text { (mL/second) }\end{array}$ \\
\hline \multicolumn{5}{|l|}{ LMM } \\
\hline Intercept & 4.161 & I33.286 & 24.476 & 6.007 \\
\hline Time $\times$ coef $_{1}$ & 0.047 & -10.181 & -0.199 & -0.012 \\
\hline Time $^{2} \times$ coef $_{2}$ & -0.004 & 0.829 & $* *$ & $* *$ \\
\hline Time $^{3} \times$ coef $_{3}$ & $* * *$ & $* * *$ & $* * *$ & $* * *$ \\
\hline Baseline & $4.23 \pm 0.32$ & $117.04 \pm 30.27$ & $22.66 \pm 5.87$ & $6.37 \pm 1.41$ \\
\hline 0.25 & $3.84 \pm 0.10$ & $176.22 \pm 12.13$ & $28.74 \pm 8.78^{\mathrm{b}}$ & $4.95 \pm 2.78$ \\
\hline I & $4.16 \pm 0.50$ & $|02.4| \pm 25.8 \mid$ & $22.42 \pm 7.00$ & $5.99 \pm 2.72$ \\
\hline 2 & $4.25 \pm 0.36$ & $120.53 \pm 38.36$ & $26.16 \pm 9.12$ & $6.88 \pm 1.96$ \\
\hline 3 & $4.26 \pm 0.35$ & $101.82 \pm 23.13$ & $23.18 \pm 8.55$ & $6.60 \pm 2.01$ \\
\hline 4 & $4.25 \pm 0.42$ & $108.59 \pm 22.17^{\mathrm{a}, \mathrm{b}}$ & $21.22 \pm 7.73$ & $6.92 \pm 2.23$ \\
\hline 5 & $4.29 \pm 0.43$ & $104.55 \pm 20.78$ & $23.11 \pm 8.55$ & $6.92 \pm 2.34$ \\
\hline 6 & $4.32 \pm 0.43$ & $1 / 2.25 \pm 20.19^{b}$ & $22.42 \pm 8.81$ & $6.38 \pm 1.55$ \\
\hline 7 & $4.28 \pm 0.36$ & $102.34 \pm 24.23$ & $25.00 \pm 13.40$ & $6.58 \pm 1.61$ \\
\hline 8 & $4.29 \pm 0.42$ & $|03.7| \pm 24.83$ & $23.44 \pm 7.58$ & $6.80 \pm 1.93$ \\
\hline 9 & $4.00 \pm 0.16$ & $110.94 \pm 25.15$ & $21.49 \pm 9.16$ & $5.91 \pm 1.68$ \\
\hline 10 & $4.13 \pm 0.20$ & I I $3.89 \pm 22.27^{b}$ & $21.72 \pm 9.44$ & $6.15 \pm 1.44$ \\
\hline
\end{tabular}

Notes: Significant differences from baseline $(P<0.05)$ are presented in bold; a'Significant difference between bolus I and 2; ${ }^{b}$ significant difference between bolus I and 3; $* *$ no quadratic time trend obvious by data assessment; ${ }^{* *}$ no cubic time trend obvious by data assessment. Linear mixed model with individual random effects and autoregressive correlation structure, which yielded the following equation: predicted value $=$ intercept $+\left(\right.$ time $\times$ coef $\left._{1}\right)+\left(\right.$ time $^{2} \times$ coef $\left._{2}\right)+\left(\right.$ time $^{3} \times$ coef $\left._{3}\right)$, where coef $_{1}=$ slope of predicted

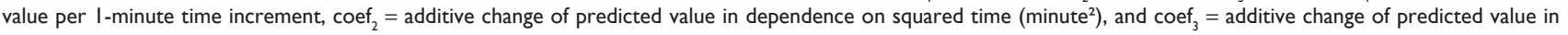
dependence on cubed time (minute ${ }^{3}$ ).

Abbreviations: LMM, linear mixed model; D, luminal diameter; psBFV, peak systolic blood-flow velocity; edBFV, end-diastolic blood-flow velocity; VFave, average volumetric flow.

Table 2 Ultrasonographic evaluation of the right common carotid artery after the second propofol bolus injection (mean \pm standard deviation)

\begin{tabular}{|c|c|c|c|c|}
\hline $\begin{array}{l}\text { Time } \\
\text { (minutes) }\end{array}$ & $\begin{array}{l}\text { D } \\
(\mathrm{mm})\end{array}$ & $\begin{array}{l}\text { psBFV } \\
\text { (cm/second) }\end{array}$ & $\begin{array}{l}\text { edBFV } \\
\text { (cm/second) }\end{array}$ & $\begin{array}{l}\text { VFave } \\
\text { (mL/second) }\end{array}$ \\
\hline \multicolumn{5}{|l|}{ LMM } \\
\hline Intercept & 4.102 & 119.715 & 23.152 & 5.906 \\
\hline Time $\times$ coef $_{\text {I }}$ & 0.100 & $-|7.07|$ & -0.032 & 0.303 \\
\hline $\mathrm{Time}^{2} \times$ coef $_{2}$ & -0.015 & 3.245 & $* *$ & -0.020 \\
\hline Time $^{3} \times$ coef $_{3}$ & 0.001 & -0.175 & $* * *$ & $* * *$ \\
\hline Baseline & $4.28 \pm 0.31$ & $103.32 \pm 16.66$ & $21.43 \pm 8.30$ & $6.69 \pm 1.56$ \\
\hline 0.25 & $3.80 \pm 0.36$ & $|48| 2 \pm 26.70$. & $28.22 \pm 9.13$ & $5.34 \pm 0.57$ \\
\hline I & $4.20 \pm 0.14$ & $90.99 \pm 20.75$ & $18.63 \pm 5.20$ & $5.47 \pm 1.00$ \\
\hline 2 & $4.27 \pm 0.25$ & $94.94 \pm 17.07$ & $22.56 \pm 9.36$ & $6.61 \pm 1.67$ \\
\hline 3 & $4.24 \pm 0.25$ & $94.9| \pm| 4.84$ & $24.14 \pm 9.37$ & $6.75 \pm 1.68$ \\
\hline 4 & $4.25 \pm 0.26$ & $94.41 \pm 14.33$ & $22.83 \pm 7.18$ & $6.67 \pm 1.61$ \\
\hline 5 & $4.27 \pm 0.29$ & $96.18 \pm|4.5|$ & $23.31 \pm 8.16$ & $7.00 \pm 1.68$ \\
\hline 6 & $4.30 \pm 0.32$ & $98.21 \pm 15.54$ & $23.28 \pm 7.56$ & $7.00 \pm 1.58$ \\
\hline 7 & $4.31 \pm 0.27$ & $97.82 \pm|7.7|$ & $24.07 \pm 8.67$ & $7.10 \pm 1.79$ \\
\hline 8 & $4.27 \pm 0.32$ & $99.72 \pm 12.87$ & $22.64 \pm 10.12$ & $6.94 \pm 2.07$ \\
\hline 9 & $4.28 \pm 0.29$ & $99.97 \pm 15.06$ & $25.12 \pm 9.17$ & $7.19 \pm 1.89$ \\
\hline 10 & $4.28 \pm 0.38$ & $99.73 \pm 13.32$ & $22.84 \pm 8.35$ & $6.90 \pm 2.02$ \\
\hline
\end{tabular}

Notes: Significant differences from baseline $(P<0.05)$ are presented in bold; **No quadratic time trend obvious by data assessment; ***no cubic time trend obvious by data assessment. Linear mixed model with individual random effects and autoregressive correlation structure, which yielded the following equation: predicted value $=$ intercept + $\left(\right.$ time $\times$ coef $\left._{1}\right)+\left(\right.$ time $^{2} \times$ coef $\left._{2}\right)+\left(\right.$ time $^{3} \times$ coef $\left._{3}\right)$, where coef $=$ slope of predicted value per I-minute time increment, coef $2=$ additive change of predicted value in dependence on squared time (minute ${ }^{2}$ ), and $\operatorname{coef}_{3}=$ additive change of predicted value in dependence on cubed time (minute ${ }^{3}$ ).

Abbreviations: LMM, linear mixed model; D, luminal diameter; psBFV, peak systolic blood-flow velocity; edBFV, end-diastolic blood-flow velocity; VFave, average volumetric flow. 
Table 3 Ultrasonographic evaluation of the right common carotid artery after the third propofol bolus injection (mean \pm standard deviation)

\begin{tabular}{|c|c|c|c|c|}
\hline $\begin{array}{l}\text { Time } \\
\text { (minutes) }\end{array}$ & $\begin{array}{l}D \\
(\mathrm{~mm})\end{array}$ & $\begin{array}{l}\text { psBFV } \\
\text { (cm/second) }\end{array}$ & $\begin{array}{l}\text { edBFV } \\
\text { (cm/second) }\end{array}$ & $\begin{array}{l}\text { VFave } \\
\text { (mL/second) }\end{array}$ \\
\hline \multicolumn{5}{|l|}{ LMM } \\
\hline Intercept & 4.209 & I I 2.770 & 28.160 & 6.717 \\
\hline Time $\times$ coef $_{1}$ & 0.049 & -12.235 & -3.556 & 0.037 \\
\hline Time $^{2} \times$ coef $_{2}$ & -0.004 & 1.968 & 0.826 & $* *$ \\
\hline Time $^{3} \times$ coef $_{3}$ & $* * *$ & -0.091 & -0.052 & $* * *$ \\
\hline Baseline & $4.33 \pm 0.30$ & $99.82 \pm 14.38$ & $24.46 \pm 7.52$ & $6.82 \pm 2.02$ \\
\hline 0.25 & $3.96 \pm 0.29$ & $139.25 \pm 30.66$ & $35.68 \pm 8.18$ & $6.42 \pm 0.96$ \\
\hline I & $4.22 \pm 0.34$ & $92.25 \pm 15.9 \mid$ & $24.00 \pm 9.12$ & $6.47 \pm 1.71$ \\
\hline 2 & $4.26 \pm 0.35$ & $94.32 \pm 12.74$ & $24.54 \pm 11.08$ & $6.79 \pm 2.07$ \\
\hline 3 & $4.24 \pm 0.37$ & $90.84 \pm 12.83$ & $25.62 \pm 9.06$ & $7.05 \pm 2.19$ \\
\hline 4 & $4.28 \pm 0.39$ & $95.00 \pm 7.18$ & $25.18 \pm 9.66$ & $6.87 \pm 2.08$ \\
\hline 5 & $4.28 \pm 0.33$ & $93.11 \pm 13.44$ & $26.53 \pm 8.81$ & $7.21 \pm 2.06$ \\
\hline 6 & $4.28 \pm 0.34$ & $88.35 \pm 16.88$ & $25.35 \pm 10.5$ & $6.91 \pm 1.99$ \\
\hline 7 & $4.27 \pm 0.37$ & $93.34 \pm|3.5|$ & $26.52 \pm 11.20$ & $7.07 \pm 2.26$ \\
\hline 8 & $4.33 \pm 0.32$ & $92.89 \pm|3.8|$ & $24.84 \pm 8.87$ & $7.09 \pm 2.10$ \\
\hline 9 & $4.28 \pm 0.36$ & $93.81 \pm 13.41$ & $26.06 \pm 10.02$ & $7.11 \pm 2.33$ \\
\hline 10 & $4.26 \pm 0.40$ & $97.01 \pm 15.26$ & $23.83 \pm 8.62$ & $6.97 \pm 2.18$ \\
\hline
\end{tabular}

Notes: Significant differences from baseline $(P<0.05)$ are presented in bold; **No quadratic time trend obvious by data assessment; ***no cubic time trend obvious by data assessment. Linear mixed model with individual random effects and autoregressive correlation structure, which yielded the following equation: predicted value $=$ intercept + $\left(\right.$ time $\times$ coef $\left._{1}\right)+\left(\right.$ time $^{2} \times$ coef $\left._{2}\right)+\left(\right.$ time $^{3} \times$ coef $\left._{3}\right)$, where coef $=$ slope of predicted value per I-minute time increment, coef ${ }_{2}=$ additive change of predicted value in dependence on squared time $\left(\right.$ minute $\left.^{2}\right)$, and coef $_{3}=$ additive change of predicted value in dependence on cubed time (minute ${ }^{3}$ ).

Abbreviations: LMM, linear mixed model; D, luminal diameter; psBFV, peak systolic blood-flow velocity; edBFV, end-diastolic blood-flow velocity; VFave, average volumetric flow.

between bolus 1 and 3 were visible 15 seconds after bolus injection in edBFV. There were also several significances at separate time points between the bolus injections in psBFV.

\section{Clinical hemodynamic parameters recorded with PiCCO technique}

Tables 4-6 show data recorded after the first, second, and third propofol bolus injections. MAP significantly and transiently decreased at 15 seconds after each propofol injection. After this rapid decrease, MAP immediately started to increase significantly compared to baseline value. HR increased significantly and transiently at the 0.25 -minute time point after bolus injections 2 and 3. Furthermore, SVRI decreased (significantly after the second and third bolus injection) at the 0.25 -minute time point, then it increased continuously and significantly until 9-10 minutes after each bolus injection. Pulse-contour CO (PCCO) and SV did not change significantly. Thermodilutional CO (TDCO) significantly decreased after an initial increase (not significant) after bolus injection 1 . When data were compared at equivalent time points after the first, second, and third bolus injections (see Tables 4 and 5), there were no significant differences between the three bolus injections comparing HR, TDCO, PCCO, and SV. Between bolus 1 and 2, as well as between bolus 1 and 3, there occurred a significant difference in
MAP 1 minute after bolus injection. The baseline values were significantly different between bolus 2 and 3. Bolus injections 1 and 2 showed significant differences in SVRI at 4, 5, 7, and 9 minutes after injection. Four minutes after bolus injection, there was an additional significant difference between bolus 1 and 3. Values for $\mathrm{SpO}_{2}, \mathrm{PetCO}_{2}$, GEDI, dPmax, blood and rectal body temperature were recorded but did not significantly change (data not shown).

\section{Discussion}

Propofol is a well-known anesthetic and often used in bolus injections to induce or prolong anesthesia or to increase anesthetic depth. The purpose of this study was to evaluate the short-term cardiovascular effects of IV propofol bolus injections in pigs using Doppler ultrasonography and the PiCCO technique.

Doppler ultrasound is a noninvasive, accurate method that can be used at the CCA for evaluation of blood flow (psBFV, edBFV, mdBFV, $\left.\mathrm{V}_{\text {mean }}\right)^{17}$ and vascular diameters. ${ }^{18,19}$ From these parameters, volumetric flow can be derived. Percutaneous ultrasonography has already been studied for its suitability to investigate vascular effects of drugs in several studies ${ }^{7,20-24}$ using goats and rabbits. The CCA is an elastictype artery like the aorta and the truncus brachiocephalicus. These blood vessels act like air vessels by retaining the 
Table 4 Clinical hemodynamic parameters recorded after the first propofol bolus injection (mean \pm standard deviation)

\begin{tabular}{|c|c|c|c|c|c|c|}
\hline $\begin{array}{l}\text { Time } \\
\text { (minutes) }\end{array}$ & $\begin{array}{l}\text { HR } \\
(\mathrm{bpm})\end{array}$ & $\begin{array}{l}\text { MAP } \\
(\mathrm{mmHg})\end{array}$ & $\begin{array}{l}\text { SVRI } \\
(\text { dyn*s*cm) }\end{array}$ & $\begin{array}{l}\text { TDCO } \\
\text { (L/minute) }\end{array}$ & $\begin{array}{l}\text { PCCO } \\
\text { (L/minute) }\end{array}$ & $\begin{array}{l}\text { SV } \\
(\mathrm{mL})\end{array}$ \\
\hline \multicolumn{7}{|l|}{ LMM } \\
\hline Intercept & 92.282 & 75.550 & 1045.570 & 5.739 & 5.670 & 60.991 \\
\hline Time $\times$ coef $_{1}$ & 0.160 & 1.254 & 42.755 & -0.232 & -0.010 & -0.221 \\
\hline Time $^{2} \times$ coef $_{2}$ & $* *$ & -0.083 & -3.575 & 0.053 & $* *$ & $* *$ \\
\hline $\mathrm{Time}^{3} \times \mathrm{coef}_{3}$ & $* * *$ & $* * *$ & $* * *$ & -0.003 & $* * *$ & $* * *$ \\
\hline Baseline & $92 \pm 10$ & $75 \pm 12$ & $1045 \pm 220$ & $5.74 \pm 1.00$ & $5.71 \pm 1.03$ & $61.33 \pm 8.73$ \\
\hline 0.25 & $96 \pm 11$ & $59 \pm 7$ & $813 \pm 209$ & $6.17 \pm 1.48$ & $5.73 \pm 1.36$ & $61.83 \pm 8.33$ \\
\hline I & $93 \pm 14$ & $78 \pm 12^{\mathrm{a}, \mathrm{b}}$ & $1128 \pm 313$ & $5.39 \pm 0.84$ & $5.72 \pm 1.3$ & $61.00 \pm 8.60$ \\
\hline 2 & $93 \pm 14$ & $79 \pm 13$ & $|17| \pm 322$ & $5.48 \pm 1.41$ & $5.41 \pm 1.06$ & $58.17 \pm 7.76$ \\
\hline 3 & $93 \pm 15$ & $80 \pm 11$ & $\mid 196 \pm 331$ & & $5.13 \pm 0.98$ & $57.60 \pm 8.44$ \\
\hline 4 & $93 \pm 15$ & $79 \pm 11$ & $1 \mid 42 \pm 262^{\mathrm{a}, \mathrm{b}}$ & $5.53 \pm 1.17$ & $5.18 \pm 0.95$ & $57.60 \pm 8.62$ \\
\hline 5 & $94 \pm 15$ & $80 \pm I I$ & $1138 \pm 247^{a}$ & & $5.59 \pm 1.29$ & $59.67 \pm 9.35$ \\
\hline 6 & $94 \pm 16$ & $8 I \pm I I$ & $1217 \pm 248$ & $5.60 \pm 1.19$ & $5.37 \pm 0.94$ & $57.17 \pm 7.83$ \\
\hline 7 & $94 \pm 14$ & $80 \pm I I$ & $1|76 \pm 22|^{a}$ & & $5.36 \pm 0.89$ & $57.50 \pm 8.12$ \\
\hline 8 & $94 \pm 14$ & $81 \pm 10$ & $1202 \pm 228$ & $5.66 \pm 1.18$ & $5.39 \pm 0.95$ & $57.50 \pm 8.48$ \\
\hline 9 & $94 \pm 13$ & $8 I \pm I I$ & $1168 \pm 206^{\mathrm{a}}$ & & $5.45 \pm 0.96$ & $58.50 \pm 8.46$ \\
\hline 10 & $94 \pm 13$ & $80 \pm 10$ & $1153 \pm 232$ & $5.61 \pm 1.05$ & $5.63 \pm 1.20$ & $59.33 \pm 9.24$ \\
\hline
\end{tabular}

Notes: Significant differences from baseline $(P<0.05)$ are presented in bold; a Significant difference between bolus I and 2; bsignificant difference between bolus I and 3; **no quadratic time trend obvious by data assessment; ***no cubic time trend obvious by data assessment. Linear mixed model with individual random effects and autoregressive

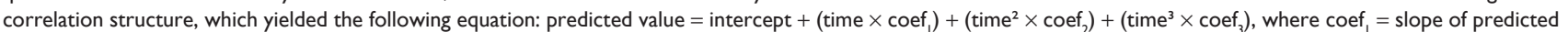

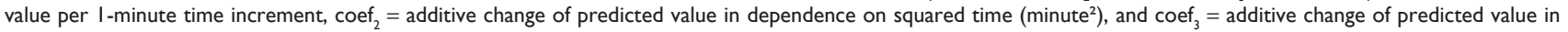
dependence on cubed time (minute ${ }^{3}$ ).

Abbreviations: LMM, linear mixed model; HR, heart rate; MAP, mean arterial pressure; SVRI, systemic vascular resistance index; TDCO, thermodilutional cardiac output; PCCO, pulse-contour cardiac output; SV, stroke volume.

pulse-waved blood and transforming the pulsatile blood flow into a continuous blood flow. ${ }^{25,26}$ Ultrasound of the CCA in this study was always performed by the same person so as to avoid variations in the examination technique. The audible and visible signals as well as the Doppler angle of $45^{\circ}-60^{\circ}$ were always comparable between the signal measurements.

Furthermore, the PiCCO technique is a well-accepted method for investigation of cardiovascular hemodynamic and volumetric parameters, including two different analysis methods: pulse-contour analysis and transcardiopulmonal thermodilution $^{8-11}$ for recording of HR, MAP, PCCO, TDCO, SV, and SVRI. Consequently, using these two methods, a detailed investigation of the short-term hemodynamic and volumetric effects of propofol bolus injections in pigs could be performed.

In the current study, a significant decrease of vessel diameter appeared at the CCA at the 0.25 -minute after each bolus injection. After bolus 1, there was a 9.2\% decrease compared to baseline, after bolus 2 an $11.2 \%$ decrease, and bolus 3 a $7.5 \%$ decrease compared to basal diameter.

The decrease of the diameter was associated with a significant increase of psBFV, which was already transient at 1 minute after injection. After these acute initial changes, vascular diameter reincreased towards baseline data and psBFV accordingly decreased after each bolus injection. Regarding the volumetric flow in the CCA, only a slight decrease was measured at the 0.25-minute after bolus injections (not significant). Therefore, propofol bolus injections induce a short-lasting decrease of the luminal diameter at the CCA that is not associated with significant changes in volumetric flow. This effect was in accordance to the findings of Nakamura et $\mathrm{al}^{27}$ and Gacar et al. ${ }^{28}$ They assume this effect might be a vasoconstriction mediated through a direct vascular effect of propofol. Nakamura et $\mathrm{al}^{27}$ studied the effect of propofol on isolated vessels of dogs; Gacar et $\mathrm{al}^{28}$ used bovine coronary artery rings in their study.

Regarding vascular changes at the peripheral distribution area of the CCA, edBFV increased at the 0.25 -minute time point after injection, indicating a decrease in peripheral vascular resistance in the distribution area of the CCA. Accordingly, PiCCO measurements showed that SVRI decreased simultaneously at the 0.25 -minute time point after injection. SVRI is the systemic vascular resistance (MAP mean right arterial pressure/CO [blood flow in system]) in relation to the body surface area. The measurement of SVRI has been conducted with the pulse-contour analysis already described, which includes a larger distribution area than the CCA has, and moreover measurements were recorded every 12 seconds. In accordance with the recorded decrease in systemic vascular resistance, MAP also significantly decreased at the 0.25 -minute after each bolus injection. This decrease was 
Table 5 Clinical hemodynamic parameters recorded after the second propofol bolus injection (mean \pm standard deviation)

\begin{tabular}{|c|c|c|c|c|c|c|}
\hline $\begin{array}{l}\text { Time } \\
\text { (minutes) }\end{array}$ & $\begin{array}{l}\text { HR } \\
\text { (bpm) }\end{array}$ & $\begin{array}{l}\text { MAP } \\
(\mathrm{mmHg})\end{array}$ & $\begin{array}{l}\text { SVRI } \\
(\text { dyn*s*cm) }\end{array}$ & $\begin{array}{l}\text { TDCO } \\
\text { (L/minute) }\end{array}$ & $\begin{array}{l}\text { PCCO } \\
\text { (L/minute) }\end{array}$ & $\begin{array}{l}\text { SV } \\
(\mathrm{mL})\end{array}$ \\
\hline \multicolumn{7}{|l|}{ LMM } \\
\hline Intercept & 95.092 & 78.987 & I I 76.427 & 5.419 & 5.790 & 60.286 \\
\hline Time $\times$ coef $_{1}$ & 0.211 & 4.828 & 212.636 & -0.253 & -0.040 & -0.345 \\
\hline $\mathrm{Time}^{2} \times \mathrm{coef}_{2}$ & $* *$ & -0.933 & -50.395 & 0.071 & $* *$ & $* *$ \\
\hline Time $^{3} \times$ coef $_{3}$ & $* * *$ & 0.050 & 3.017 & -0.004 & $* * *$ & $* * *$ \\
\hline Baseline & $96 \pm 13$ & $79 \pm 8^{a}$ & $1086 \pm 179$ & $5.53 \pm 1.06$ & $5.87 \pm 1.28$ & $60.83 \pm 10.05$ \\
\hline 0.25 & $103 \pm 10$ & $57 \pm 4$ & $680 \pm|3|$ & $7.42 \pm 2.46$ & $5.87 \pm 1.58$ & $61.67 \pm 10.78$ \\
\hline I & $91 \pm 11$ & $85 \pm 8$ & $|338 \pm 23|$ & $5.09 \pm 0.82$ & $5.37 \pm 1.15$ & $59.20 \pm 9.18$ \\
\hline 2 & $93 \pm 13$ & $86 \pm 8$ & $1337 \pm 223$ & $5.08 \pm 0.86$ & $4.96 \pm 0.81$ & $55.40 \pm 9.07$ \\
\hline 3 & $93 \pm 14$ & $86 \pm 8$ & $1337 \pm 227$ & & $4.99 \pm 0.82$ & $55.20 \pm 9.36$ \\
\hline 4 & $94 \pm 14$ & $86 \pm 8$ & $1333 \pm 213$ & $5.37 \pm 0.89$ & $4.97 \pm 0.8 I$ & $55.20 \pm 9.28$ \\
\hline 5 & $94 \pm 13$ & $85 \pm 8$ & $1327 \pm 202$ & & $4.98 \pm 0.83$ & $55.20 \pm 9.76$ \\
\hline 6 & $95 \pm 14$ & $85 \pm 7$ & $|29| \pm 200$ & $5.25 \pm 0.80$ & $5.15 \pm 0.96$ & $56.20 \pm 9.52$ \\
\hline 7 & $95 \pm 14$ & $84 \pm 7$ & $|27| \pm 197$ & & $5.17 \pm 0.86$ & $56.40 \pm 9.81$ \\
\hline 8 & $96 \pm 14$ & $84 \pm 7$ & $1263 \pm 184$ & $5.70 \pm 1.10$ & $5.16 \pm 0.85$ & $56.20 \pm 10.03$ \\
\hline 9 & $96 \pm 14$ & $84 \pm 7$ & $|23| \pm 182$ & & $5.27 \pm 0.85$ & $57.00 \pm 9.03$ \\
\hline 10 & $97 \pm 14$ & $84 \pm 7$ & $1233 \pm 178$ & $5.39 \pm 0.86$ & $5.30 \pm 0.88$ & $57.40 \pm 9.07$ \\
\hline
\end{tabular}

Notes: Significant differences from baseline $(P<0.05)$ are presented in bold; aSignificant difference between bolus 2 and 3 ; **no quadratic time trend obvious by data assessment; ***no cubic time trend obvious by data assessment. Linear mixed model with individual random effects and autoregressive correlation structure, which yielded

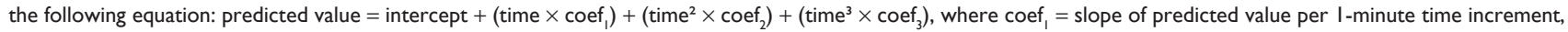
coef $_{2}=$ additive change of predicted value in dependence on squared time (minute ${ }^{2}$ ), and $\operatorname{coef}_{3}=$ additive change of predicted value in dependence on cubed time $\left(\right.$ minute ${ }^{3}$ ). Abbreviations: LMM, linear mixed model; HR, heart rate; MAP, mean arterial pressure; SVRI, systemic vascular resistance index; TDCO, thermodilutional cardiac output; PCCO, pulse-contour cardiac output; SV, stroke volume.

transient because after this acute change at the 0.25 -minute, MAP and SVRI significantly increased compared to baseline data until 10 minutes after bolus injection. The decrease in SVRI combined with a significant decrease in MAP after propofol bolus injection was also observed by Ambros et al, ${ }^{29}$ who showed that SVR decreases during propofol anesthesia. They induced and maintained anesthesia with propofol in dogs for 120 minutes. The measurements were recorded after baseline values 5 minutes after induction of anesthesia. They explained this finding as direct venodilatory effects causing a reduction in preload. Blake et $\mathrm{al}^{30}$ explained the decrease in total peripheral resistance in terms of a reduction of resting constrictor tone. In an experiment with propofol in dogs, Brussel et $\mathrm{al}^{31}$ recorded a reduction in SVR 1 minute after bolus injection of propofol. They explained this reduction in SVR as a vasodilating effect of propofol on mainly arteries and arterioles rather than on veins. They conducted anesthesia with ketamine and fentanyl and administered one propofol bolus injection after a 3-4 hour stabilization period. Hemodynamic parameters were measured $1,3,5$, and 10 minutes after administration of propofol. Muzi and Berens ${ }^{32}$ assumed in their study in humans that the increased rate of filling of the forearm vein is strong evidence for arterial vasodilation because of the administered propofol for induction and as a continuous infusion. Pagel and Warltier ${ }^{33}$ also discovered a decrease in SVR, believing both venous and arterial vessels to be dilated. They studied systemic hemodynamics and myocardial contractility in conscious state and after a bolus of propofol, followed by propofol infusion for 15 minutes at different dosages. However, in the present study, the measured decrease of systemic vascular resistance and MAP after propofol bolus injection was only short-lasting, and both parameters significantly reincreased over baseline data until the end of the investigation period, indicating well-preserved cardiovascular function directly after propofol bolus injection in pigs.

Accordingly, HR significantly increased at the 0.25 -minute time point after propofol bolus injections 2 and 3. This transient increase of HR was most likely induced by the significant drop in SVRI and MAP and therefore led to unchanged SV and a slight increase of CO (TDCO, PCCO). A possible reason for this short-lasting tachycardia could be a reflectory reaction on decreasing MAP (significant), possibly induced by the reduction of systemic vascular resistance. In contrast to our results, many studies reported decreased HR after propofol anesthesia. ${ }^{34,35}$ Possible reasons are that these studies investigated a longer period of time compared to our study. Accordingly, Ambros et $\mathrm{al}^{29}$ showed that HR decreased after initiation of anesthesia with propofol in dogs receiving propofol over 120 minutes. Baroreceptors, which constantly 
Table 6 Clinical hemodynamic parameters recorded after the third propofol bolus injection (mean \pm standard deviation)

\begin{tabular}{|c|c|c|c|c|c|c|}
\hline $\begin{array}{l}\text { Time } \\
\text { (minutes) }\end{array}$ & $\begin{array}{l}\text { HR } \\
\text { (bpm) }\end{array}$ & $\begin{array}{l}\text { MAP } \\
(\mathrm{mmHg})\end{array}$ & $\begin{array}{l}\text { SVRI } \\
(\text { dyn*s*cm) }\end{array}$ & $\begin{array}{l}\text { TDCO } \\
\text { (L/minute) }\end{array}$ & $\begin{array}{l}\text { PCCO } \\
\text { (L/minute) }\end{array}$ & $\begin{array}{l}\text { SV } \\
(\mathrm{mL})\end{array}$ \\
\hline \multicolumn{7}{|l|}{ LMM } \\
\hline Intercept & 96.850 & 81.693 & 1117.927 & 5.616 & 5.906 & 60.107 \\
\hline Time $\times$ coef $_{\mathrm{I}}$ & -0.358 & 3.357 & 90.753 & 0.004 & -0.051 & -0.436 \\
\hline Time $^{2} \times$ coef $_{2}$ & 0.064 & -0.640 & -16.358 & $* *$ & $* *$ & $* *$ \\
\hline Time $^{3} \times$ coef $_{3}$ & $* * *$ & 0.034 & 0.838 & $* * *$ & $* * *$ & $* * *$ \\
\hline Baseline & $98 \pm 15$ & $83 \pm 6$ & $1126 \pm 172$ & $5.74 \pm 0.95$ & $5.76 \pm 1.02$ & $58.83 \pm 6.91$ \\
\hline 0.25 & $106 \pm 10$ & $61 \pm 7$ & $660 \pm 173$ & $7.59 \pm 2.54$ & $6.29 \pm 2.75$ & $62.17 \pm 16.17$ \\
\hline I & $96 \pm 15$ & $86 \pm 6$ & $1172 \pm 376$ & $5.26 \pm 0.94$ & $6.27 \pm 2.70$ & $63.83 \pm 17.29$ \\
\hline 2 & $95 \pm 16$ & $86 \pm 6$ & $1244 \pm 318$ & $5.28 \pm 1.00$ & $5.73 \pm 1.84$ & $59.17 \pm 10.26$ \\
\hline 3 & $95 \pm 16$ & $86 \pm 6$ & $1280 \pm 278$ & & $5.45 \pm 1.41$ & $56.83 \pm 8.54$ \\
\hline 4 & $95 \pm 16$ & $87 \pm 6$ & $1254 \pm 258$ & $5.66 \pm 1.26$ & $5.55 \pm 1.33$ & $57.83 \pm 7.68$ \\
\hline 5 & $96 \pm 16$ & $86 \pm 5$ & $1238 \pm 257$ & & $5.56 \pm 1.24$ & $58.00 \pm 7.21$ \\
\hline 6 & $97 \pm 16$ & $86 \pm 5$ & $1240 \pm 245$ & $5.41 \pm 0.90$ & $5.59 \pm 1.34$ & $57.67 \pm 8.41$ \\
\hline 7 & $97 \pm 16$ & $86 \pm 5$ & $|239 \pm 2| \mid$ & & $5.43 \pm 0.96$ & $56.00 \pm 8.32$ \\
\hline 8 & $98 \pm 16$ & $85 \pm 5$ & $|234 \pm| 8 \mid$ & $5.54 \pm 0.85$ & $5.47 \pm 0.93$ & $56.50 \pm 8.12$ \\
\hline 9 & $98 \pm 16$ & $85 \pm 6$ & $1199 \pm 187$ & & $5.58 \pm 0.92$ & $57.33 \pm 7.76$ \\
\hline 10 & $99 \pm 16$ & $85 \pm 5$ & $1219 \pm 165$ & $5.58 \pm 0.83$ & $5.51 \pm 0.84$ & $56.33 \pm 8.55$ \\
\hline
\end{tabular}

Notes: Significant differences from baseline $(P<0.05)$ are presented in bold; **No quadratic time trend obvious by data assessment; ***no cubic time trend obvious by data assessment. Linear mixed model with individual random effects and autoregressive correlation structure, which yielded the following equation: predicted value $=$ intercept + $\left(\right.$ time $\left.\times \operatorname{coef}_{1}\right)+\left(\right.$ time $\left.^{2} \times \operatorname{coef}_{2}\right)+\left(\right.$ time $\left.^{3} \times \operatorname{coef}_{3}\right)$, where coef $=$ slope of predicted value per I-minute time increment, coef ${ }_{2}=$ additive change of predicted value in dependence on squared time $\left(\right.$ minute $\left.{ }^{2}\right)$, and coef $_{3}=$ additive change of predicted value in dependence on cubed time (minute ${ }^{3}$ ).

Abbreviations: LMM, linear mixed model; HR, heart rate; MAP, mean arterial pressure; SVRI, systemic vascular resistance index; TDCO, thermodilutional cardiac output; PCCO, pulse-contour cardiac output; SV, stroke volume.

monitor blood pressure in the vessel walls, communicate with the cardiovascular control center (CCC), which is located in the medullary region of the brain. Changes in blood pressure affect the frequency of action potentials sent to the CCC from the baroreceptors. The CCC responds to changes in baroreceptor input by initiating compensatory mechanisms that restore blood pressure back to normal. A decrease in blood pressure causes a decrease in action potentials sent to the CCC, which leads to an increase in sympathetic input. This causes reduction of vessel diameter and increased HR and $\mathrm{SV}$, resulting in a rise in blood pressure by increasing total peripheral resistance as well as $\mathrm{CO} .{ }^{36}$ Propofol does affect the baroreceptor reflex, producing decreasing HR despite lower blood pressure. ${ }^{30}$ In our study, we recorded during the acute phase (0.25 minute) a significant drop in MAP while HR significantly increased, which indicates a good persistence of baroreceptor reflex.

SV did not change significantly during the investigated period of 10 minutes. Three different parameters affect stroke volume: preload, afterload, and contractility. Preload - in our study represented as SVV - did not change during the experiment. The afterload, represented in our study by SVRI, decreased significantly at the 0.25 -minute time point. At the same time point, $\mathrm{HR}$ and consequently $\mathrm{CO}$ increased, which leads to the assumption that the contractility of the heart is not negatively affected by the investigated propofol bolus injections. PiCCO also measures the parameters dPmax, GEF, and CFI, which define the contractility of the heart. They did not change significantly; consequently, a change in myocardial contractility during propofol anesthesia can be ruled out according to PiCCO measurement. In contrast to our findings, Brussel et $\mathrm{al}^{31}$ and Pagel and Warltier ${ }^{33}$ supposed a direct negative effect of propofol on the myocardium based on their results of both a decreased cardiac output and decreased MAP. Pagel and Warltier ${ }^{33}$ used a sensitive method to evaluate myocardial contractility, which is relatively independent of changes in HR and preload and insensitive to changes in afterload, ${ }^{37}$ but their first measurement began at 15 minutes after propofol infusion rate had been started.

There are some limitations to the present study. To assess differences between the value for each time point during the 10-minute time frame after the propofol bolus injection and the baseline value, multiple post hoc Student $t$-tests for paired samples were used. Because the probability of detecting false-significant differences (differences by chance) increases with the number of tests conducted, adjustment of $P$-values for the number of comparisons made would have increased the likelihood of a type II error, and a considerably larger sample size would have been necessary to yield sufficient power for a detailed analysis. For that reason, 
we decided to use nonadjusted $P$-values as statistical measures of importance, and we consider our results explorative.

Because of the intense reaction of the vessels directly after the bolus injection of propofol, the hemodynamic measurement by thermodilution was technically only possible at 1 minute after bolus injection. In between, the continuous pulse-contour values of PiCCO were taken for analysis of data (SVRI, CO, MAP, HR). Gruenewald et $\mathrm{al}^{38}$ showed that intraabdominal hypertension affects the precise measurement of PiCCO. In a study performed by Piehl et al, ${ }^{39}$ rapid changes in blood pressure or intravascular volume led to imprecise values of PiCCO. After recalibration with thermodilution, $\mathrm{PiCCO}$ values in both studies were again accurate.

To investigate the baroreceptor reflex, it would have been necessary to do a pressor/depressor test with vasoactive drugs like sodium nitroprussid and phenylephrine. ${ }^{40}$ However, with the use of those drugs, the direct visible vascular effect of a propofol bolus investigated by sonography would have been masked.

Additionally, we preliminarily tested the effect of saline bolus injections with vascular ultrasound without a propofol bolus injection and can rule out any influence on our measurements.

\section{Conclusion}

In summary, propofol bolus injections immediately (at time point 0.25 minute) caused a significant decrease in vessel diameter at the CCA after each bolus injection. Simultaneously, psBFV, edBFV, and HR significantly increased, while MAP and SVRI significantly decreased. After these acute initial changes, vascular diameter reincreased towards baseline data and psBFV significantly decreased, while MAP and SVRI significantly increased until 10 minutes after bolus injection.

Bolus injections of propofol produced biphasic vascular and hemodynamic changes in pigs. However, these alterations were only associated with minor changes in $\mathrm{CO}$ and did not lead to significant changes of volumetric flow, indicating well-preserved function of the cardiovascular system, particularly the baroreceptor reflex, within the first 10 minutes after propofol bolus injection. Moreover, no cumulative effect was evident when comparing the data between the three bolus injections.

Propofol can be used safely in common practice, but should be used carefully in pigs with ventricular dysfunction.

\section{Disclosure}

The authors report no conflicts of interest in this work.

\section{References}

1. Buech HP, Buech U. Narkotika [Narcotics]. In: Forth W, Henschler D, Rummel W, Starke K, editors. Allgemeine und Spezielle Pharmakologie und Toxikologie [General and special pharmacology and toxicology]. Mannheim: BI Wissenschaftsverlag; 1992:249-250.

2. Haberstroh J, Henke J, Baumgartner C. Kaninchen [Rabbits]. In: Erhardt W, Henke J, Haberstroh J, Baumgartner C, Tacke S, editors. Anästhesie und Analgesie beim Klein- und Heimtier [Anesthesia and analgesia in the small and exotic animal]. Stuttgart: Schattauer; 2011:688-702.

3. Erhardt W, Henke J, Tacke S, Baumgartner C, Kroker R. Allgemeinanästhetika [Anesthetics for general anesthesia]. In: Erhardt W, Henke J, Haberstroh J, Baumgartner C, Tacke S, editors. Anästhesie und Analgesie beim Klein- und Heimtier [Anesthesia and analgesia in the small and exotic animal]. Stuttgart: Schattauer; 2011:44-48.

4. Smith I, White PF, Nathanson M, Gouldson R. Propofol. An update on its clinical use. Anesthesiology. 1994;81:1005-1043.

5. Fish RE. Pharmacology of injectable anesthetics. In: Kohn DW, Wixson SK, White GJ, Benson GJ, editors. Anesthesia and Analgesia in Laboratory Animals. London: Academic Press; 1997:8-9.

6. Mayer M, Ochmann A, Doenicke R, Angster R, Suttmann H. The effect of propofol-ketamine anesthesia on hemodynamics and analgesia in comparison with propofol-fentanyl [German]. Anaesthesist. 1990;39: 609-616.

7. Baumgartner C, Bollerhey M, Henke J, Wagner S, Ungerer M, Erhardt W. Effects of propofol on ultrasonic indicators of haemodynamic function in rabbits. Vet Anaesth Analg. 2008;35:100-112.

8. Band DM, Linton RAF, O'Brien TK, Jonas MM, Linton NW. The shape of indicator dilution curves used for cardiac output measurement in man. J Physiol. 1997;498(1):225-229.

9. Wesseling KH, Jansen JR, Settels JJ, Schreuder JJ. Computation of aortic flow from pressure in humans using a nonlinear, three-element model. J Appl Physiol. 1993;74:2566-2573.

10. Buhre W, Weyland A, Kazmeier S, et al. Comparison of cardiac output assessed by pulse contour analysis and thermodilution in patients undergoing minimally invasive direct coronary artery bypass grafting. J Cardiothorac Vasc Anesth. 1999;13:437-440.

11. Reuter DA, Goetz AE. Measurement of cardiac output. Anaesthesist. 2005;54:1135-1151.

12. Hueter L, Schwarzkopf K, Preussler NP, et al. Measuring cardiac output in one-lung ventilation: a comparison of pulmonary artery and transpulmonary aortic measurements in pigs. $J$ Cardiothorac Vasc Anesth. 2004;18:190-193.

13. Ruperez M, López-Herce J, García C, Sánchez C, García E, Vigil D. Comparison between cardiac output measured by the pulmonary arterial thermodilution technique and that measured by the femoral arterial thermodilution technique in a pediatric animal model. Pediatr Cardiol. 2004;25:119-123.

14. López-Herce J, Ruperez M, Sánchez C, García C, García E. Correlation between cardiac output measured by the femoral arterial thermodilution technique pulmonary arterial and that measured by contour pulse analysis in a paediatric animal model. J Clin Monit Comput. 2006;20:19-23.

15. Bajorat J, Hofmockel R, Vagts DA, et al. Comparison of invasive and less-invasive techniques of cardiac output measurement under different haemodynamic conditions in a pig model. Eur J Anaesthesiol. 2006; 23:23-30.

16. Stiegler H, Klews PM. Hämodynamische Grundlage [Basic hemodynamics]. In: Kubale R, Stiegler H, editors. Farbkodierte Duplexsonographie [Color-coded duplex sonography]. Stuttgart: Thieme; 2002:93.

17. Widder B, Görtler M. Doppler- und Duplexsonographie der hirnversorgenden Arterien [Doppler and duplex sonography of brainsupplying arteries]. Heidelberg: Springer Verlag; 2004:21.

18. Mueck-Weymann M, Wupperman T. Physiologie und Pathophysiologie des Blutflusses [Physiology and pathophysiology of blood flow]. In: Wupperman T, editor. Sonographie der Gefaesse [Sonography of vessels]. Munich: Urban and Fischer; 1999:21-27. 
19. Lin GS, Spratt RS. Hemodynamic imaging with pulsatility index and resistive index color Doppler US. Radiology. 1997;204:870-873.

20. Lee SW, Hankes GH, Purohit RC, et al. Comparative study of ultrasonography and arteriography of the carotid artery of xylazine-sedated and halothane-anesthetized goats. Am J Vet Res. 1990;51:109-113.

21. Baumgartner C, Koenighaus H, Ebner J, Henke J, Schuster T, Erhardt W. Cardiovascular effects of fentanyl and propofol on hemodynamic function in rabbits. Am J Vet Res. 2009;70:409-417.

22. Baumgartner CM, Koenighaus H, Ebner JK, Henke J, Schuster T, Erhardt WD. Cardiovascular effects of dipyrone and propofol on hemodynamic function in rabbits. Am J Vet Res. 2009;70:1407-1415.

23. Baumgartner C, Bollerhey M, Ebner J, Laacke-Singer L, Schuster T, Erhardt W. Effects of ketamine-xylazine intravenous bolus injection on cardiovascular function in rabbits. Can J Vet Res. 2010;74:200-208.

24. Baumgartner C, Bollerhey M, Ebner J, Schuster T, Henke J, Erhardt W. Effects of medetomidine-midazolam-fentanyl IV bolus injections and its reversal by specific antagonists on cardiovascular function in rabbits. Can J Vet Res. 2010;74:286-298.

25. Carroll BA. Carotid sonography. Radiology. 1991;178:303-313.

26. Liebich HG. Funktionelle Histologie der Haussaengetiere und Voegel [Functional histology of companion animals and birds]. Stuttgart: Schattauer; 2010:135-136.

27. Nakamura K, Hatano Y, Hirakata H, Nishiwada M, Toda H, Mori K. Direct vasoconstrictor and vasodilator effects of propofol in isolated dog arteries. Br J Anaesth. 1992;68:193-197.

28. Gacar N, Goek S, Kalyoncu NI, Ozen I, Soykan N, Aktuerk G. The effect of endothelium on the response to propofol on bovine coronary artery rings. Acta Anaesthesiol Scand. 1995;39:1080-1083.

29. Ambros B, Duke-Novakovski T, Pasloske K. Comparison of the anesthetic efficacy and cardiopulmonary effects of continuous rate infusions of alfaxalone-2-hydroxypropyl- $\beta$-cyclodextrin and propofol in dogs. Am J Vet Res. 2008;69:1391-1398.
30. Blake DW, Jover B, McGrath BP. Haemodynamic and heart rate reflex responses to propofol in the rabbit. Comparison with althesin. $\mathrm{Br} J$ Anaesth. 1988;61:194-199.

31. Brussel T, Theissen JL, Vigfusson G, Lunkenheimer PP, Van Aken H, Lawin P. Hemodynamic and cardiodynamic effects of propofol and etomidate: negative inotropic properties of propofol. Anesth Analg. 1989;69:35-40.

32. Muzi M, Berens RA. Venodilation contributes to propofol-mediated hypotension in humans. Anesth Analg. 1992;74:877-883.

33. Pagel PS, Warltier DC. Negative inotropic effects of propofol as evaluated by the regional preload recruitable stroke work relationship in chronically instrumented dogs. Anesthesiology. 1993;78:100-108.

34. Claeys MA, Gepts E, Camu F. Haemodynamic changes during anesthesia induced and maintained with propofol. Br J Anaesth 1998;60:3-9.

35. Sebel P, Lowdon J. Propofol: a new intravenous anesthetic. Anesthesiology. 1989;71:260-277.

36. Sherwood L. Human Physiology: From Cells to Systems. Delmont: Brooks/Cole; 2010:378-379.

37. Glower DD, Spratt JA, Snow ND, et al. Linearity of the Frank-Starling relationship in the intact heart: the concept of preload recruitable stroke work. Circulation. 1985;71:994-1009.

38. Gruenewald M, Renner J, Meybohm P, Höcker J, Scholz J, Bein B. Reliability of continuous cardiac output measurement during intraabdominal hypertension relies on repeated calibrations: an experimental animal study. Crit Care. 2008;12:R132.

39. Piehl MD, Manning JE, McCurdy SL, et al. Pulse contour cardiac output analysis in a piglet model of severe hemorrhagic shock. Crit Care Med. 2008;36:1189-1195.

40. Buhre W, Hoeft A. Anaesthesia and the cardiovascular system. In: Priebe HJ, Skarvan K, editors. Cardiovascular Physiology. 2nd ed. London: BMJ Books; 2000:338.
Open Access Animal Physiology

\section{Publish your work in this journal}

Open Access Animal Physiology is an international, peer-reviewed, open access journal publishing original research, reports, reviews and commentaries on all areas of animal physiology. The manuscript management system is completely online and includes a very

\section{Dovepress}

quick and fair peer-review system. Visit http://www.dovepress.com/ testimonials.php to read real quotes from published authors. 